\title{
Analysis on the Practical Teaching Quality Assurance System of Preschool Education Specialty in Colleges
}

\author{
Jianyan Huang \\ Baoshan University, Baoshan Yunnan, 678000, China
}

Keywords: Preschool education, Practical teaching, Quality assurance.

\begin{abstract}
As the preschool education specialty cultivates preschool teachers with professional skills, its teaching quality concerns the establishment of China's preschool teacher teams. Especially, the practical teaching for preschool education specialty relates to the preschool teachers' ability and quality. Therefore, it is required to construct the practical teaching quality assurance system for preschool education specialty in colleges and fully enhance the teaching quality and efficiency of preschool education specialty in colleges of our country. This paper analyzes the importance and current situation of practical teaching for preschool education specialty in colleges and discusses how to construct the practical teaching quality assurance system for preschool education specialty in China's colleges.
\end{abstract}

\section{Introduction}

As an important part of China's educational system, preschool education mainly continuously promote children's intelligence development and cultivate their good learning habits through scientific and interesting teaching methods. The preschool education specialty in colleges aims to specially train professional preschool education talents with high quality and high capability for the society and is a branch of education science; it's teaching task is to conclude the experience in preschool education, study the theories regarding preschool education and use foreign preschool education theories and practices for reference to help the nursery schools, kindergartens and families for children education and provide scientific guidance for cultivation of a new high-quality generation. The teaching content of preschool education is mainly to learn the basic theories and knowledge concerning preschool education and accept the basic training related to children education so as to have the basic ability in childcare, education and research in kindergarten units. At present, the teaching for preschool education specialty in China mainly places emphasis on the teaching of theories and knowledge; as for the practical teaching for this specialty, students mainly need to practice during winter and summer vacations so they lack teachers' guidance; the practical teaching quality for preschool education cannot be guaranteed and the students cultivated cannot adapt to the preschool education in the new era. For this reason, it is very necessary to construct the practical teaching quality assurance system for preschool education specialty. In this way, the system can help students majoring in preschool education to learn the content of preschool education specialty and related skills from theories to practices, comprehensively enhance students' ability of children education and cultivate more preschool teachers with high quality and capability for the society. This paper seeks for effective strategies for the construction of practical teaching quality assurance system for preschool education specialty based on the importance of practical teaching quality assurance for preschool education specialty and its existing problems.

\section{Importance of practical teaching for preschool education specialty in colleges}

As an important part of China's educational system, preschool education mainly continuously promote children's intelligence development and cultivate their good learning habits through scientific and interesting teaching methods. The preschool education specialty in colleges aims to specially train professional preschool education talents with high quality and high capability for the society and is a branch of education science; it's teaching task is to conclude the experience in 
preschool education, study the theories regarding preschool education and use foreign preschool education theories and practices for reference to help the nursery schools, kindergartens and families for children education and provide scientific guidance for cultivation of a new high-quality generation ${ }^{[1]}$. The teaching content of preschool education is mainly to learn the basic theories and knowledge concerning preschool education and accept the basic training related to children education so as to have the basic ability in childcare, education and research in kindergarten units.

Compared with the western developed countries, China's development degree of preschool education specialty is relatively low and the advanced western concepts and teaching methods have been continuously introduced over the recent years. Many colleges also began to provide courses for preschool education specialty and made great progress in educational practice and scientific research to further scientifically exhibit the law of preschool education. Under the influence of the Chinese traditional educational concept, the current preschool education specialty in China's colleges still emphasizes the learning of theoretical knowledge and neglects the cultivation of students' practical education to some extent so it fails to cultivate students' all-dimensional preschool education ability. However, from the perspectives of the development of preschool education and cultivation of students, colleges' emphasis on the cultivation of practical teaching for students majoring in preschool education is of great significance. Firstly, it can cultivate more preschool teachers with practical ability for the society and help students to continuously improve their teaching ability and innovate in teaching concepts by accumulating experience and use knowledge in practical teaching. Secondly, it can effectively enhance the teaching quality of preschool education specialty; the implementation of practical teaching not only increases the learning interestingness but also provides more diversified teaching methods for preschool education specialty so as to fully stimulate students' learning initiative and enhance the teaching quality. Finally, the implementation of practical teaching for preschool education specialty can facilitate the construction of China's social spirit and culture; besides, practical teaching for preschool education can not only enhance students' learning quality but also indirectly promote the development of China's early childhood education; it facilitates the construction of China's social spirit and culture from"childhood" and can better realize the great rejuvenation of Chinese nation.

\section{Current situation of practical teaching for preschool education specialty in colleges}

With the introduction of the concept of preschool education, China's educational circle has been increasingly emphasizing the development of preschool education and the country also issued all sorts of preferential policies to encourage the implementation of preschool education. This not only greatly enhanced the quality of China's preschool education but also provided college students majoring in preschool education with better opportunities for employment and development. However, due to the outdated views, teaching conditions and assessment management etc. in practical teaching for preschool education specialty in colleges, the professional competence of students majoring in preschool education needs to be further improved.

\section{Outdated teaching concepts}

Many college teachers for preschool education ideologically make light of practical teaching, consider it as a teaching link, simply let students to independently complete the teaching practice through educational probation and internship and fail to integrate practical teaching into the college's curriculum setting, teachers' whole process of education and teaching as well as students' whole learning process, so that students' educational internship is not targeted and standard ${ }^{[2]}$. Secondly, many teachers impart the concept of practical teaching of observing and learning educational skills to students, fail to research students' psychological characteristics and neglect students' subjective experience and the cultivation of the quality of imparting knowledge and educating people. Thirdly, during the process of practical teaching for preschool education specialty, teachers neglect the process of active construction of students' own development so that students' knowledge theories are 
separate from educational practice; as a result, the important function of practical teaching for preschool education is not achieved.

\section{Single teaching content and form}

Since the practical teaching for preschool education specialty in colleges was started, teachers have only considered it as a verification link rather than fully stimulated students' exploration on new knowledge and new theories. Besides, the teaching forms only include teaching probation and teaching internship and teachers only pay attention to the improvement of students' educational skills in their teaching content. After the educational probation ends, they don't carry out scientific assessment and management over students. Some colleges even just go through the motions for the implementation of practical teaching for preschool education and only complete the teaching objective in form without emphasizing the importance of practical teaching.

\section{Backward teaching conditions}

The difficulty in conducting practical teaching for preschool education specialty in China's colleges is largely because the backward conditions for practical teaching. Restrained by the economic conditions, some colleges lack a high-quality practical base and high-quality teaching staff so that students can only conduct practical teaching through their own connections; as a result, it shows a current situation that there is neither experimental and practical training module on campus nor relatively stable internship base outside colleges. Meanwhile, many college teachers fail to make valuable evaluation on the effect of students' practical teaching because they also lack experience in practical teaching and thus the practical teaching for preschool education specialty in China's colleges only became a mere formality.

\section{Lack of overall standard management and assessment}

The outdated teaching idea, single teaching form and lack of teaching conditions of practical teaching for colleges' preschool education specialty resulted in the unsound practical teaching assurance mechanism, imperfect system, unscientific evaluation, the failure to form a complete practical teaching system on the macro level and the lack of evaluation mechanism for practical teaching quality on the micro level. Besides, this also leaded to the great randomness of practical teaching for preschool education specialty and the lack of standard management and evaluation on students, so it's difficult to truly attain the teaching results and objectives of practical teaching.

\section{Strategies for construction of practical teaching quality assurance system for preschool education specialty in colleges}

Based on the analysis on the current situation of practical teaching for preschool education specialty in colleges of China, we can know that China's current practical teaching for preschool education specialty lacks a certain quality assurance system and students fail to fully use the theoretical knowledge they've learned in the process of practice and to show the major advantage of professional talents in preschool education so as to lose opportunities for employment and development. Therefore, it is of vital significance to construct the efficient practical teaching quality assurance system for preschool education specialty in colleges. Besides, it is required to comprehensively build the system from the teaching concept, content, conditions and evaluation etc. so as to really realize the teaching significance of practical teaching for preschool education specialty.

\section{To update the teaching concept and establish the new concepts of"overall situation" and"reflection"}

In order to build the practical teaching quality assurance system for preschool education specialty, colleges must update the concept of practical teaching and establish the new concepts such as"whole course","experience" and reflection ${ }^{[3]}$. The so-called"whole course" refers to putting practical teaching through the whole learning process from new students' entrance to their graduation under the 
guidance of theoretical education, and systematically localizing and making overall arrangements for all practical contents as a whole; the so-called"experience", which is interpreted from the perspective of psychology, refers to the beautiful feeling generated in one's consciousness when one's emotion, physical strength, intelligence and even spirit reach a given level or an individual's special feeling for the response to some stimuluses;"reflection" means self-reflection and self-observation. The practical teaching with overall-situation experience and reflection means that teachers help students to get personally in a certain practical teaching environment through meticulous social scene teaching in the overall process of practice; with the scientific guidance and enlightenment, teachers can intensify students' practical experience, unconsciously promote students to apply the theories and knowledge they've learned in teaching practice and reflect on and observe their own practical teaching results to some extent so that teachers can form related cognition of the comprehensive implementation and value and can help students to achieve the unification of theories and practice in practical teaching.

\section{To enrich the teaching content and formulate specific implementation schemes}

Under the guidance of teaching theory of"overall-situation experience and reflection", the teachers for preschool education specialty in colleges also need to actively make innovations in the teaching content of practical teaching, make students to continuously experience the charm and knowledge points of preschool education in the whole learning process and thus comprehensively enhance students' theoretical knowledge and practical ability ${ }^{[4]}$. To be specific, an implementation scheme should be made from the following aspects: firstly, standardize the classroom teaching practice, fully pay attention to the learning guidance for students' mandarin, foreign language, computer and art class, let students to learn cursorily all sorts of disciplinary knowledge and enhance students' basic teaching skills for preschool education; secondly, carry out educational practice for extracurricular activities; during the educational practice for extracurricular activities, improve students' professional ability and skills through specific activities, enhance their vocational skills, such as"story-telling","painting" and"handcraft", give fully play to students' expertise and encourage students to actively devote themselves to the learning and training of expertise; thirdly, provide educational practices of participation, observation and simulation, create conditions for students to observe the course practice of high-quality preschool teachers and stimulate students' learning interest by making them to practically contact with kindergartens.

To safeguard the conditions for practical teaching and lay emphasis on the construction of practical bases and talent teams

Guaranteeing sufficient conditions for practical teaching and emphasizing the construction of practical bases and talent teams are the important means to realize the practical teaching for preschool education specialty. Only in this way, can the practical teaching be conducted better so that students can have time and place to fully do teaching practice and comprehensively enhance their professional ability. The conditions for practical teaching mainly include hardware conditions, construction of practical training bases and talent resources; namely, when guaranteeing sufficient on-campus physical training bases and off-campus practical training bases, it is also required to establish a high-quality talent team and enhance the professional quality of preschool education teachers in colleges. Therefore, colleges need to increase their capital investment in practical teaching for preschool education and, meanwhile, establish cooperative relationships with all kindergartens and nursery organizations, which then can serve as students' off-campus training bases. For the construction of teaching staff, it is required to provide teachers with occupational training at regular intervals, enhance their professional quality and timely introduce advanced professional concept of preschool education.

To establish a scientific and complete practical teaching quality evaluation and assurance system

A scientific and complete practical teaching quality assessment and assurance system can effectively evaluate students' results of practical teaching and thus promote their better development. 
Specifically, it is required to formulate a comprehensive, detailed and high operable quality assessment indicator system based on the link of practical teaching content and the due ability structure of preschool teachers, and adopt the"two-line, four-level and two-combination" evaluation system $^{[5]}$. The two-line means the monitoring through the college's evaluation and the kindergarten's evaluation; four-level mean the four-level monitoring system through students' supervision, the spot check of the practical training office of the dean's office, the department's teaching and research office's inspection and students' evaluation on teaching; the two-combination means the combination between daily spot check and phased inspection. In this way, we can evaluate students' practical teaching quality from the college and kindergarten so as to promote and encourage students to do effective teaching practice.

\section{Conclusion}

The practical teaching for preschool education specialty in colleges can greatly help to enhance students' professional teaching ability and facilitate their development and employment of preschool education in a better way. Colleges need to comprehensively promote students to actively carry out diversified practical teaching, enhance the quality of preschool education and facilitate the rapid development of China's preschool education by altering the teaching concept, enriching the teaching content, optimizing the teaching conditions and perfecting the evaluation system in the preschool education.

\section{Reference}

[1] Chen Lin. Research on quality assurance of educational practice bases of the specialty of undergraduate preschool education, Southwest University, 2014.

[2] Hu Qiuyun. Research on reform and practice of the cultivation mode of higher vocational preschool education professionals, Xiamen Univeresity, 2013.

[3] Cheng Xiulan and Zhen Junfang. Problems in teaching for preschool education specialty of colleges in Shaanxi province and their solutions, Studies in Preschool Education, 2011, 06: 3-8.

[4] Lai Zhiqun and Xie Zeyuan. Thought on the construction of practical teaching quality assurance system for preschool education specialty in higher vocational colleges, Career Horizon, 2014, 07: 15-17.

[5] Kong Min. Brief discussion on the construction of course system of practical teaching for preschool education specialty in colleges, New Curriculum Research (midmonth magazine), 2016, 03: 22-24. 